\title{
Peripheral Neuroectodermal Tumor Presenting Pleural Effusion
}

\author{
Kazuyoshi Kurashima*, Shingo Muramoto*, Yasuhiko Ohta**, Masaki FujImura*** and Tamotsu Matsuda***
}

Pleural effusion is a common finding of peripheral neuroectodermal tumor (PNET) of the chest wall (Askin's tumor), but little is known about the characteristics. A case of Askin's tumor with pleural effusion is reported. Repeated cytologies were negative for malignancy, but levels of lactic dehydrogenase (LDH) and neuron-specific enolase (NSE) in the pleural effusion were increased. Surgical biopsy was performed and immunohistochemical study of the tumor revealed the diagnosis.

(Internal Medicine 33: 783-785, 1994)

Key words: chest wall, Askin's tumor

\section{Introduction}

Peripheral neuroectodermal tumor (PNET) is a rare, highly malignant small cell neoplasm that most often arises from the chest wall or paravertebral region. This entity is well recognized by pathologists but has been described rarely in the clinical journals. Clinical and radiological aspects of the tumor are not well documented, which may delay the correct diagnosis. To draw notice to this tumor, we report a case of PNET of the chest wall presenting with pleural effusion, which could not be diagnosed by repeated aspiration cytologies.

\section{Case Report}

A 26-year-old man was admitted to our hospital in January 1993 with left chest pain, cough and low grade fever persisting for a few days. Physical examination revealed decreased expansion, dull percussion note and reduced breath sounds over the left lower thorax. Laboratory data on admission (Table 1) showed no remarkable change except for mild anemia. A chest radiograph showed left-sided pleural effusion. Pleuritis was diagnosed but there was no response to antibiotics. Computed tomography on January 2 and February 4 (Fig. 1) revealed left pleural effusion but there was no mass or bone abnormality. Pleural biopsies and examinations of pleural effusion (Table 2) showed no malignant cells, but increased levels of lactic dehydrogenase (LDH), adenosine deaminase (ADA) and neuron-specific enolase (NSE). Computed tomography and magnetic resonance computed tomography on May 12 demonstrated a mixed attenuation mass with internal fluid and pleural effusion (Fig. 2). No obvious involvement of lymph nodes, bone or diaphragm could be identified. An open surgical biopsy confirmed the diagnosis of PNET. Light microscopy showed small round tumor cells with hyperchromatic nuclei and scanty cytoplasm (Fig. 3a). Rosettes were also found. Periodic-acidSchiff stain (PAS) was negative. Immunohistochemistry of the tumor demonstrated that the tumor was positive for NSE (Fig. $3 b$ ), synaptophysin and vimentin (data not shown). The patient received two courses of combination chemotherapy utilizing cisplatin $(110 \mathrm{mg} / \mathrm{day} 1)$ and etoposide (100 mg/day 1, 2, 3). The tumor shrunk remarkably. Currently, he is receiving radiotherapy to the chest wall (55 Gy).

\section{Discussion}

The differential diagnosis of childhood and adolescent tumors composed of small round cells has classically involved Ewing's sarcoma, neuroblastoma, lymphoma, rhabdomyosarcoma and peripheral neuroectodermal tumor (PENT). PNET of the chest wall is now called Askin's tumor $(1,2)$. Histologically, it may be impossible to distinguish this tumor from other small round cell tumors and diagnosis may be established by immunohistochemical and electron microscopical features as discussed by Steiner (3). Diagnostically, the most characteristic and significant findings are the presence of rosettes and cytoplasmic staining for NSE (4). However, NSE-positive small cell carcinoma can not be distinguished without the localization of the tumor and other immunohistochemical features, such as synaptophysin, vimentin, etc (5). In this case, the tumor was an extrapulmonary mass, and synaptophysin and vimentin were

From ****the Internal Medicine and Surgery, Noto General Hospital, Nanao and ***the Third Department of Internal Medicine, Kanazawa University, School of Medicine, Kanazawa

Received for publication December 7, 1993; Accepted for publication August 9, 1994

Reprint requests should be addressed to Dr. Kazuyoshi Kurashima, the Third Department of Internal Medicine, Kanazawa University, School of Medicine, Kanazawa 920 
KurASHima et al

Table 1. Laboratory Data on Admission

\begin{tabular}{lrlr}
\hline Peripheral blood & & Alakline phosphatase & $106 \mathrm{IU} / \mathrm{L}$ \\
White blood cell count & $6,800 / \mathrm{ul}$ & Blood urea nitrogen & $10 \mathrm{IU} / \mathrm{L}$ \\
neutrophil & $63 \%$ & Creatinine & $1.2 \mathrm{IU} / \mathrm{L}$ \\
basophil & $0 \%$ & $\mathrm{Na}$ & $143 \mathrm{mEq} / \mathrm{L}$ \\
eosinophil & $3 \%$ & $\mathrm{~K}$ & $4.6 \mathrm{mEq} / \mathrm{L}$ \\
monocyte & $10 \%$ & $\mathrm{Cl}$ & $106 \mathrm{mEq} / \mathrm{L}$ \\
lymphocyte & $24 \%$ & $\mathrm{NSE}$ & $6.3 \mathrm{ng} / \mathrm{ml}$ \\
Red blood cell count & $437 \times 10 / \mu \mathrm{l}$ & Squamous cell cancer antigen & $3.3 \mathrm{ng} / \mathrm{ml}$ \\
Hemoglobin & $12.5 \mathrm{~g} / \mathrm{dl}$ & & \\
Hematocrit & $36.4 \%$ & $\mathrm{Blood}^{2}$ gas analysis & \\
Platelet & $37.3 \times 10 / \mu \mathrm{l}$ & $\mathrm{pH}$ & 7.415 \\
Erythrocyte sedimentation ratio & $27 \mathrm{~mm} / 1 \mathrm{~h}$ & $\mathrm{PaCO}_{2}$ & $42.2 \mathrm{mmHg}$ \\
& & $\mathrm{PaO}_{2}$ & $82.5 \mathrm{mmHg}$ \\
Blood chemistry & & & $124 \mu \mathrm{gg} / \mathrm{day}$ \\
Total protein & $6.2 \mathrm{~g} / \mathrm{dl}$ & Urinary total \\
Aspartate aminotransferase & $11 \mathrm{IU} / \mathrm{L}$ & catecholamine & \\
Alanine aminotransferase & $7 \mathrm{IU} / \mathrm{L}$ & & \\
Lactic dehydrogenase & $339 \mathrm{IU} / \mathrm{L}$ & & \\
\hline
\end{tabular}

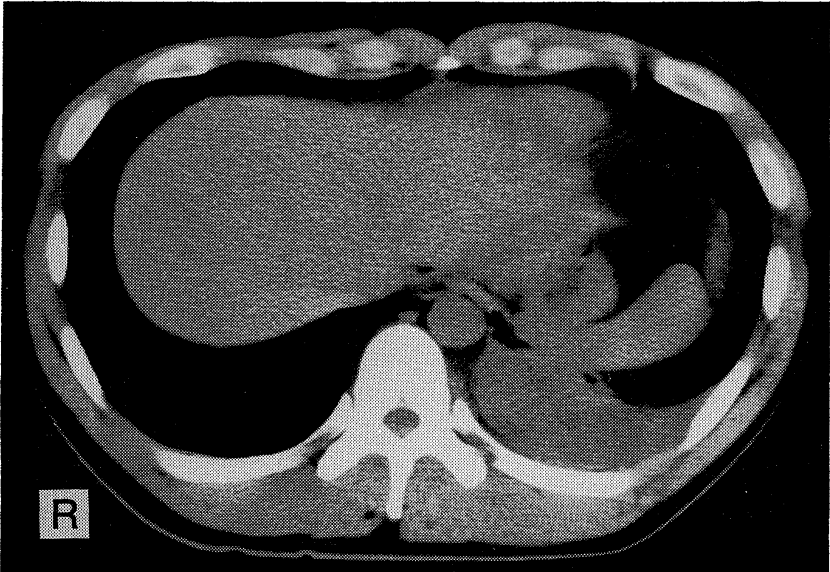

Fig. 1. Computed tomography on February 4 revealed left pleural effusion but there was no mass nor bone abnormality.

Table 2. Data of Pleural Effusions

\begin{tabular}{|c|c|c|c|c|}
\hline & January 18th & March 10th & April 26th & May 11th \\
\hline Appearance & Bloody & Bloody & Bloody & Bloody \\
\hline Protein & $5.5 \mathrm{~g} / \mathrm{dl}$ & $5.3 \mathrm{~g} / \mathrm{dl}$ & $4.9 \quad \mathrm{~g} / \mathrm{dl}$ & $2.8 \mathrm{~g} / \mathrm{ml}$ \\
\hline Sugar & $99 \mathrm{mg} / \mathrm{dl}$ & $78 \mathrm{mg} / \mathrm{dl}$ & $54 \mathrm{mg} / \mathrm{dl}$ & $34 \mathrm{mg} / \mathrm{ml}$ \\
\hline $\begin{array}{l}\text { Lactic dehydro- } \\
\text { genase }\end{array}$ & $2,546 \mathrm{IU} / \mathrm{L}$ & $8,970 \mathrm{IU} / \mathrm{L}$ & $5,500 \mathrm{IU} / \mathrm{L}$ & $5,940 \mathrm{IU} / \mathrm{L}$ \\
\hline Amylase & $\mathrm{IU} / \mathrm{L}$ & $\mathrm{IU} / \mathrm{L}$ & $\mathrm{IU} / \mathrm{L}$ & IU/L \\
\hline $\begin{array}{l}\text { Adenosine } \\
\text { deaminase }\end{array}$ & $\mathrm{U} / \mathrm{L}$ & $\mathrm{U} / \mathrm{L}$ & 41.2 & 68.1 \\
\hline NSE & & $\mathrm{ng} / \mathrm{ml}$ & & $\mathrm{ng} / \mathrm{ml}$ \\
\hline \multicolumn{5}{|l|}{ Cell subsets } \\
\hline Neutrophils & $14 \%$ & $80 \%$ & $69 \%$ & $59 \%$ \\
\hline Lymphocytes & $15 \%$ & $20 \%$ & $26 \%$ & $35 \%$ \\
\hline Histiocytes & $41 \%$ & $0 \%$ & $0 \%$ & $0 \%$ \\
\hline Eosinophils & $30 \%$ & $0 \%$ & $5 \%$ & $6 \%$ \\
\hline Cytology & Negative & Negative & Negative & Negative \\
\hline Culture & Negative & Negative & Negative & Negative \\
\hline Rheumatic factor & & & $<18 \mathrm{IU} / \mathrm{L}$ & \\
\hline Hyaluronic acid & & & Negative & \\
\hline
\end{tabular}

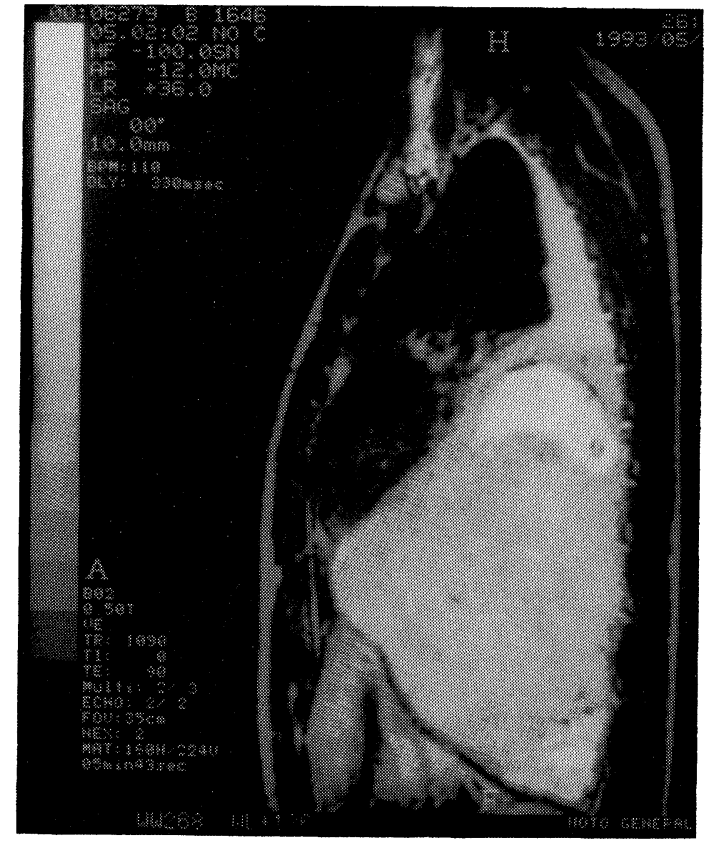

Fig. 2. Sagittal thoracic MRI image (1.5 Tesra magnet, spin echo TR 1,090/TE90, 5 mm slice thickness) on May 13 demonstrated the high signal intensity left thoracic mass and pleural effusion.

also positive.

PNET of the chest wall is a very rare tumor in adults. Saifuddin et al summarized 46 cases of Askin's tumor (6) and 16 cases have been reported in Japan (7). The pathology of the tumor has been discussed in detail $(1,2)$, but little attention has been given to clinical and radiological aspects. The most common presenting symptom, in just over half the cases, is a painful chest wall mass. Chest pain without a mass is also common. Cough and dyspnea are less frequent features. Constitutional symptoms such as fever, anorexia and weight loss 


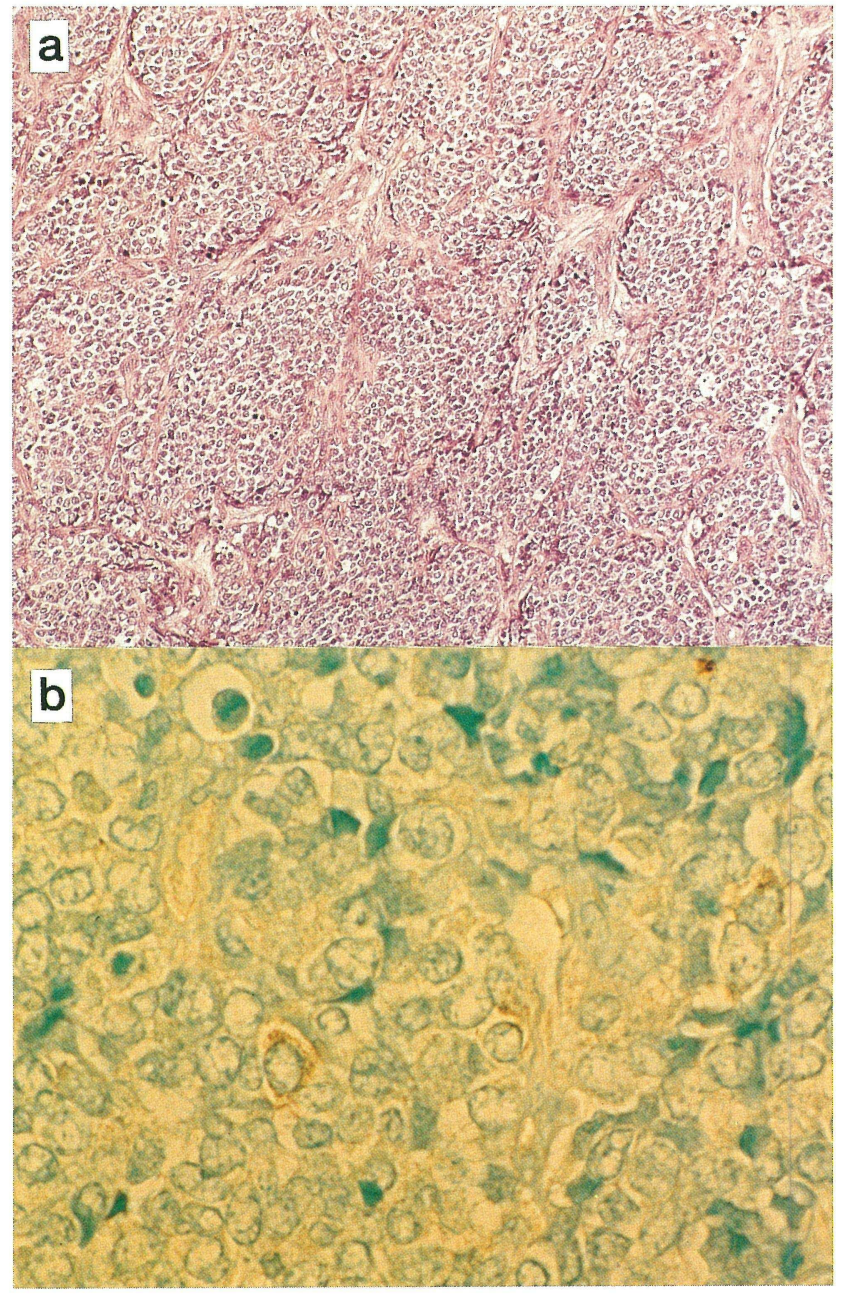

Fig. 3. a) The hematoxylin-eosin stained slides demonstrated small round cells with sparse cytoplasm $(\times 100)$. b) Immunostaining for NSE demonstrated cytoplasmic staining $(\times 400)$.

may occur. Other modes of presentation are much more rare (6).

The most common radiological feature is a chest wall mass of soft tissue density, present in approximately two-thirds of cases (8). Over half of these have local rib destruction. Pleural effusion is a common radiological finding (70\%), but the characteristics of pleural effusion are rarely known $(8,9)$. In the present case, the pleural effusion was bloody throughout the course, and LDH, ADA and NSE in pleural effusion were elevated, however, repeated cytologies of the effusions were negative for malignant cells. Immunohistochemistry of the tumor and elevated levels of NSE in pleural effusions strongly supported the diagnosis, but negativity for NSE of tumor cells does not exclude the diagnosis because NSE is a soluble cytoplasmic constituent (4). Regarding the past literature, there were few case reports of PNET in which pleural effusion was positive for malignant cells (10). This seems to be important especially when pleural effusion is the only manifestation of the disease.

The Most common CT findings are extensive mixed attenuation soft tissue mass, associated rib destruction and pleural fluid (6). It should be emphasized that in the present case, the initial radiological sign was pleural effusion and chest wall mass was not been detected for over 3 months. In summary, PNET must be considered in the differential diagnosis of chest wall mass or unexplained pleural effusion in children and in young adults.

\section{References}

1) Askin FB, Rosai J, Sibley RK, Dehner LP, McAlister WH. Malignant small cell tumor of the thoracopulmonary region in childhood. Cancer 43: 2438, 1979.

2) Gonzalez-Crussi F, Wolfson SL, Misugi K, Nakajima T. Peripheral neuroectodermal tumors of the chest wall in childhood. Cancer 54: 2519, 1984.

3) Steiner GC. Neuroectodermal tumor versus Ewing's sarcomaimmunohistochemical and electron microscopic observations. Current Topics in Pathology 80: 1, 1989.

4) Hashimoto H, Kiryu H, Enjoji M, Daimaru Y, Nakajima T. Malignant neuroepithelioma. Am J Surg Pathol 7: 309, 1983.

5) Silverman JF, Berns LA, Holbrook CT, Neil JSA, Joshi VV. Fine Needle aspiration cytology of primitive neuroectodermal tumors. Acta Cytologica 36: 541, 1992.

6) Saifuddin A, Robertson RJH, Smith SEW. The radiology of Askin tumors. Clinical Radiology 43: 19, 1991.

7) Matsue I, Sasaki F, Murano A, Inaba Y, Washio S, Kido C. A case of malignant small cell tumor of the tracopulmonary region in childhood. Jpn J Clin Radiol 38: 307, 1993.

8) Fink M, Salisbury J, Gishen P. Askin tumor: three case histories and a review of the literature. Eur J Radiology 14: 178, 1992.

9) Burge HJ, Novotny DB, Schiebler ML, Delany DJ, McCartney WH. MRI of Askin's tumor - case report at 1.5T. Chest 97: 1253, 1990.

10) Faubert $C$, Inniger R. MRI and pathological findings in two cases of Askin tumors. Neuroradiology 33: 277, 1991. 